\title{
GRUPOS DE ESTUDOS COLETIVOS PARA A FORMAÇÃO DOCENTE CONTINUADA: Experiência Realizada no CEIM Páscoa* no Contexto de Pandemia da COVID-19
}

\section{COLLECTIVESTUDY GROUPS FOR CONTINUOUS TEACHER EDUCATION:} Experience Conducted at CEIM Páscoa in the Context of the COVID-19

\section{Pandemic}

\author{
Maristela da Rosa \\ Secretaria Municipal de Educação de Biguaçu/ \\ $\mathrm{SC}$ \\ E-mail: maristeladarosasc@gmail.com \\ Nadja Regina Sousa Magalhães \\ Especialista em Assuntos Educacionais \\ Biguaçu, Santa Catarina, BR \\ Orcid.org/0000-0003-1349-4487 \\ E-mail: nadjamagalhaes78@gmail.com
}

\section{INTRODUÇÃ̃O}

Se, na experiência de minha formação, que deve ser permanente, começo por aceitar que o formador é o sujeito em relação a quem me considero o objeto, que ele é o sujeito que me forma e eu, o objeto por ele formado, me considero como um paciente que recebe os conhecimentos/conteúdos acumulados pelo sujeito que sabe e que são a mim transferidos. Nesta forma de compreender e de viver o processo formador, eu, objeto agora, terei a possibilidade, amanhã, de me tornar o falso sujeito da "formação" do futuro objeto de meu ato formador. É preciso que, pelo contrário, desde os começos do processo, vá ficando cada vez mais claro que, embora diferentes entre si, quem forma se forma e re-forma ao formar e quem é formado forma-se e forma ao ser formado (FREIRE, 1996, p. 12, grifo nosso).

O contexto da pandemia Covid-19 nos fez entrar em um mundo totalmente diferente, de inseguranças e de possibilidades. A Organização

*Centro de Educação Infantil Municipal Professora Páscoa Régis Mendes. 
Mundial de Saúde - OMS, em 11 de março de 2020, em razão da disseminação da doença infecciosa causada por um novo coronavírus em todos os continentes, nos fez pensar a respeito das nossas vidas pessoais e profissionais. A Rede Municipal de Ensino de Biguaçu nos desafiou a trabalhar remotamente, além de atendermos as crianças por meio das tecnologias. Mantendo o vínculo e a interação com elas e com as suas famílias, teríamos também a formação docente continuada descentralizada a distância (BIGUAÇU, 2020b).

Em Santa Catarina, o governo estadual, por meio do Decreto Estadual no 515, de 17 de março de 2020 (SANTA CATARINA, 2020), afirma uma situação de emergência em todo o território catarinense que levou à suspensão das aulas em todas as escolas das redes de ensino para fins de prevenção e enfrentamento à COVID-19. Em consonância a esta normativa, o governo municipal de Biguaçu também deflagrou emergência, e estabeleceu medidas de prevenção e combate ao vírus, por meio do Decreto Municipal n 69, de 18 de março de 2020 (BIGUAÇU, 2020c), que regulamentou os horários e as escalas de trabalho na Administração do município biguaçuense.

No contexto educacional, além de decretos e normativas já citadas, a Secretaria Municipal de Educação de Biguaçu -SEMED baseou-se em medidas apontadas pela Lei de Diretrizes e Bases da Educação - LDB, no 9394/96, ao destacar, no artigo $23, \S 2$, que o calendário escolar deverá adequar-se às peculiaridades locais, inclusive climáticas e econômicas, a critério do respectivo sistema de ensino, e com isso reduzir o número de horas letivas previsto nesta Lei (BRASIL, 2017).

A educação municipal seguiu orientações também da Medida Provisória no 934, do Governo Federal, de 1o de abril de 2020 (BRASIL, 2020b), que estabeleceu normas excepcionais sobre o ano letivo da Educação Básica (Educação Infantil) decorrentes das medidas para enfrentamento da situação de emergência de saúde pública de que trata a Lei no 13.979, de 6 de fevereiro de 2020 (BRASIL, 2020c). Com esta Medida Provisória, ocorreu a autorização para flexibilização do Calendário Escolar, desobrigando os estabelecimentos de ensino da Educação Básica do Brasil a cumprirem os 200 dias efetivos de trabalho escolar, mas mantendo a obrigatoriedade da carga horária mínima de 800 horas para completar o ano letivo. 
O Plano de Atendimento Emergencial para Rede Municipal de Educação (BIGUAÇU, 2020a) considerou também como orientação aquelas medidas propostas pelo Conselho Nacional de Educação - CNE, "sobre Reorganização dos Calendários Escolares e realização de Atividades Pedagógicas não Presenciais durante o período de Pandemia da Covid-19", em que os estudos focaram em análises, já prevendo a possibilidade de longa duração da suspensão das atividades escolares presenciais. Ao tratarem da Educação Infantil, afirmou-se:

Para realização de atividades pedagógicas não presenciais, sugere-se que as instituições de Educação Infantil possam elaborar orientações/sugestões aos pais ou responsáveis sobre atividades que possam ser realizadas com seus filhos durante o período de isolamento social. Deve-se, ainda, admitir a possibilidade de tornar o contato com os pais, tutores e responsáveis pelas atividades mais efetivo com o uso de internet, celular ou mesmo de orientações de acesso síncrono ou assíncrono. A escola, por sua vez, deverá definir a oferta do instrumento de resposta e feedback. Essa possibilidade se configura possível mesmo para a rede pública em todos ou determinados municípios ou localidades (BRASIL, 2020a, p. 07).

Com todos esses acontecimentos, a proposta deste artigo surgiu da nossa participação em reuniões de comitê realizadas com representantes da SEMED, gestores, especialistas em assuntos educacionais e professores da rede, via plataformas assíncronas como: Google Meet e Skype, em meio à pandemia. Diante deste cenário, a rede municipal de ensino publicou:

A Instrução Normativa n. 01 de 09 de abril de 2020, instituindo a criação de 04 comitês para discutir, deliberar e pensar a reorganização do calendário escolar, sendo eles: GT1 - ensino fundamental - anos finais; GT2 - ensino fundamental - anos iniciais; GT3 - Educação Infantil e GT4 - educação de jovens e adultos. A composição dos grupos de trabalhos foi composta pelas seguintes representações: especialistas em assuntos educacionais da Secretaria Municipal de Educação; representantes de professores do ensino fundamental anos iniciais e anos finais; representantes dos professores da Educação Infantil; representantes dos professores da educação de jovens e adultos; representante do Conselho Municipal de Educação; representante do Sindicato dos Trabalhadores Municipais; representantes dos especialistas em assuntos educacionais da rede municipal e diretores das unidades escolares municipais (BIGUAÇU, 2020a, p. 07).

O Plano de Atendimento Emergencial objetivou "nortear as ações pedagógicas, pautadas na proposta curricular da rede municipal para a Educação 
de Biguaçu" (BIGUAÇU, 2020a, p. 08). No que tange às questões pedagógicas, houve a necessidade de instituir um projeto de formação continuada para Educação Infantil ${ }^{1}$ que objetivou "propor um estudo e planejamento coletivo a partir dos currículos construídos/indicados pela legislação Nacional da Educação Infantil, bem como temáticas ligadas à Proposta Curricular do município de Biguaçu" (BIGUAÇU, 2020a, p. 424).

Portanto, a formação docente continuada da Educação Infantil de Biguaçu iniciou no contexto de pandemia, mas considerou, para o estudo, as temáticas que vinham sendo discutidas nos anos de 2018 e 2019, com a reformulação da proposta curricular da Educação Infantil municipal. Isso corrobora o que foi apresentado no projeto de formação continuada proposto via setor da Educação infantil - SEMED, com temáticas para estudo, nos Centros de Educação Infantil de Biguaçu, em que poderíamos dirimir as temáticas a partir das necessidades de cada instituição escolar:

Tema 1: os campos de experiencias na educação infantil; Tema 2: diretrizes curriculares nacionais para a educação infantil; parecer do conselho nacional de educação no 5/2020 e os artigos da LDB no 9.394/96; Tema 3: os conceitos de infância e criança na educação infantil; Tema 4: a educação infantil e relações étnico - raciais e de gênero; Tema 5: o ensino infantil em uma perspectiva de educação especial e inclusiva; Tema 6: a organização dos tempos e espaços na educação infantil; Tema 7: a educação infantil à luz de um olhar interdisciplinar; Tema 8: as práticas pedagógicas e os processos avaliativos na educação infantil; Tema 9: a importância das famílias e do ensino no desenvolvimento e transições na infância; Tema 10: O projeto político pedagógico na educação infantil (BIGUAÇU, 2020a, p. 426).

Com esta proposição nos faz pensar: será que a educação não precisa ser pensada, questionada? Que formação temos e queremos? Percebemos que as temáticas apontadas elencam temas que perpassam nossas práticas, mas existe a necessidade de serem repensados no coletivo e de que maneira contribuirão nos espaços educativos.

Ao partirmos desse contexto de formação continuada, que iniciou um movimento de estudos nos Centros de Educação Infantil municipal e destacamos o CEIM Páscoa, que sentiu a necessidade de contextualizar, junto com o

\footnotetext{
${ }^{1}$ O projeto na íntegra encontra-se no anexo VII do Plano de Atendimento Emergencial para Rede Municipal de Educação (2020).
} 
grupo de profissionais, a importância de continuarmos aprendendo para além da formação inicial, isto é, manter viva a semente dos trabalhos coletivos e troca de diferentes saberes em diferentes espaços, por meio de grupos de estudos coletivos, pois a prática pedagógica e experiências são imprescindíveis, sendo que também buscamos nas concepções epistemológicas e metodológicas os conhecimentos necessários para nos ajudar a entender o mundo e os processos educacionais.

Portanto, essa tessitura objetiva divulgar o trabalho pedagógico que vem sendo desenvolvido na rede municipal de ensino; analisar a estratégia da Secretaria Municipal de Educação de Biguaçu no sentido da formação docente continuada, e sublinhar os grupos de estudos coletivos como tática do CEIM Páscoa para este fim.

Enfatizamos que, mesmo com a flexibilização do ensino segundo a formação continuada e aulas remotas, não podemos perder de vista a importância do ser professor, bem como do contato presencial, que nesse momento foram interrompidos com o ensino em EaD em todo país, conforme ressalta Soares (2020, p. 06-07):

Quando se anuncia a chegada da COVID-19 no Brasil um dos primeiros passos dos governantes para "conter" o vírus é decretar o fechamento das escolas, simbolizando assim que a situação não estava "normal". Os prazos dos decretos seguem sendo ampliados e a pressão pela continuidade dos estudos fez com que se tirasse da gaveta um projeto que há muito tempo fazia parte das aspirações dos governos e empresas privadas de educação: a educação a distância (EAD). Do dia para a noite essa modalidade que até então era proibida como ferramenta prioritária na educação básica, torna-se a solução pragmática para o momento da crise pandêmica. [...] Nesse contexto, a possibilidade de que o ensino deixe de ser centrado na escola enquanto estrutura física e possa se dar no ambiente virtual é uma das grandes apostas do neoliberalismo para a modernização da educação.

Nesse sentido, precisamos refletir que desdobramentos e estratégias estão sendo traçadas para educação e, sobretudo, para a formação de professores e crianças que estão na Educação Infantil. Na compreensão de Martins (2020, p. 15), "nós, educadoras/es, temos vivenciado nos últimos anos ataques ferozes à educação que estão dentro de uma ampla política de privatização e mercantilização da educação no Brasil". 
Com isso, a formação docente continuada poderá ser envolvida na obtenção de conhecimento voltado para atender a estas expectativas pautadas nessa forma de fazer educação no contexto brasileiro.

Portanto, a relevância científica deste artigo é servir de aporte para novas pesquisas que tratam do tema, bem como pensar o currículo, a formação e a constituição da infância na Educação Infantil e em destaque como os grupos de estudos coletivos de formação continuada no CEIM Páscoa se afetam para subsidiar a prática pedagógica.

\section{CAMINHOS METODOLÓGICOS: Formação continuada na constituição dos professores como pesquisadores}

[...] Quem pesquisa? [...] além dos formadores e de instituições não universitárias, a própria pessoa em formação, legitimada a se formar mais pela produção de conhecimento fundado em suas práticas e experiências, do que pelo consumo de conhecimentos produzido sobre elas (PASSEGGl, 2016, p. 76).

Esta tessitura de abordagem qualitativa e de cunho bibliográfico e documental baseia-se no aporte teórico do campo da formação docente e nos currículos prescritos nacionais e municipais, bem como em documentos escolares que organizaram e registraram todo o processo de formação continuada descentralizada a distância, a partir de grupos de estudos coletivos no CEIM Páscoa.

A reflexão sobre o ser e estar professor nos encaminha para viver estes processos não apenas pelos conhecimentos adquiridos na vida acadêmica, mas partimos também das experiências de vida pessoal e profissional que acontecem na trajetória dos sujeitos. Por isso, "essa indissociabilidade do sujeito do conhecimento e do autoconhecimento é importante para conceber os professores em formação" (PASSEGGI, 2016, p. 71).

Ao aliarmos nossas práticas por intermédio da pesquisa, precisamos saber quais os significados e os sentidos de ser um professor pesquisador; entender os porquês de se fazer pesquisa como parte da formação docente. $\mathrm{Na}$ perspectiva da pesquisa-formação, podemos dizer que:

[...] no modelo da pesquisa-formação destacam-se três objetivos principais: o objetivo da compreensão teórica; o objetivo praxeológico de engenharia e de 
estratégia de formação; e o objetivo emancipatório. Entendo que o último é o mais importante dos três, pois se trata de perceber a pesquisa como parte integrante da formação e não alheia a ela, pois a pesquisa é o que torna possível o processo de conscientização de formar-se com e pela pesquisa. Do ponto de vista axiológico, a dicotomia entre compreensão teórica e aplicação prática é substituída pela inclusão do objetivo emancipatório de conscientização e autonomização, que levará incondicionalmente em conta as experiências individuais de aprendizagem do sujeito da formação (PASSEGGI, 2016, p. 75).

Ao partir do que foi ressaltado anteriormente, podemos dizer que a pesquisa narrativa como formação encanta os pesquisadores que percorrem os campos das abordagens das pesquisas autobiográficas e história de vida. A experiência constitui o conceito central da pesquisa-formação com o uso de narrativas.

Nesse contexto, afirmamos que todo professor pode se colocar na condição de sujeito biográfico. A pesquisa-formação tem uma potência política incrível, tanto pela intervenção quanto pela criticidade diante da realidade. Na pesquisa-formação, o ser é paralelamente sujeito e objeto da pesquisa, o que permite que o pesquisador se desloque para o centro da pesquisa e passe a conhecer a si próprio.

Os principais conceitos que utilizamos como lentes teóricas - ou como categorias - para analisar nosso objeto de estudo foram emprestados do historiador francês Michel de Certeau (1994), que faz uso das concepções de estratégias e táticas, as quais traz do campo militar e as ressignifica da seguinte forma: "Estratégia, engajada em sistematizar e impor ordem", é compreendida como:

O cálculo (ou a manipulação) das relações de forças que se torna possível a partir do momento em que o sujeito de querer e poder (uma empresa, um exército, uma cidade, uma instituição científica) pode ser isolado. A estratégia postula um lugar suscetível de ser circunscrito como algo próprio e ser a base de onde podem gerir as relações com uma exterioridade de alvos ou ameaças (os clientes, ou os concorrentes, os inimigos, o campo em torno da cidade, os objetivos e objetos da pesquisa etc.) (CERTEAU, 2014, p. 93 grifo do autor).

Em direção oposta, na sua concepção, a tática se configura como:

A ação calculada que é determinada pela ausência de um próprio. Então nenhuma delimitação de fora Ihe fornece a condição de autonomia. A tática não 
tem por lugar senão o do outro. E por isso deve jogar com o terreno que the é imposto tal como o organiza e a lei de uma força estranha. Não tem meios para se manter em si mesma, 'a distância, numa posição recuada, de previsão e de convocação própria: a tática é movimento "dentro do campo de visão do inimigo". A tática é a arte do fraco (CERTEAU, 1994, p. 94-95).

A partir de Certeau (1994), podemos compreender que a operação realizada pelas estratégias produz e impõe, enquanto a das táticas manipula, altera e torna possível o convívio com aquilo que é imposto. Pretendemos analisar, então, como a equipe do CEIM Páscoa criou um espaço de jogo (os grupos de estudos coletivos) para fazer uso e se apropriar taticamente daquilo que lhe foi imposto como estratégia: a formação docente continuada descentralizada a distância.

Ao tratarmos de formação docente continuada em tempos de pandemia e que nos desloca através da estratégia do ensino remoto, nos conduz a pensar não apenas em nossa formação, mas também como está se constrói nos diversos modos de viver.

São nos momentos de reflexividade em histórias de vida em que nos reconhecemos e constituímos nossa identidade como pessoas e como professores. Nóvoa (2009) descreve que a formação é algo que pertence ao próprio sujeito e se inscreve num processo de ser (nossas vidas e experiências) e em processo de ir sendo (nossa ideia de futuro). A história que contamos nos traz as marcas das histórias que nos contaram e nos constituíram. Por meio da reflexividade da prática e da formação docente é possível narrar as experiências em curso que são transformadoras e delineadas também pelos desenhos curriculares compostos desde a formação inicial que subjaz nas diretrizes curriculares nacionais para formação de professores que vem sendo apresentada na atualidade:

No campo da disputa de projetos que se apresenta, desafiar a dominação passa por afirmar o imperativo de uma formação geral e profissional ampla que permita aos professores o domínio dos conhecimentos que lhes cabe socializar e o discernimento para decidir o que é bom ensino e as finalidades a que ele deve servir. (ANPED et al., 2019).

Almejamos pensar na formação continuada como reflexividade da prática que norteia a profissionalidade docente em um contexto crítico, social e histórico, muito além dos cursos de curta duração e dos currículos prescritos 
que vem sendo imposto nos discursos das atuais políticas de formação docente, através de uma formação inicial de professores para a Educação Básica vem desconstruir políticas educacionais já consolidadas nesse âmbito. Portanto, os coletivos de professores carecem se manter vivos nas discussões que se instauram em todos os espaços educacionais que venham traçar os rumos da formação docente.

\section{GRUPOS DE ESTUDOS COLETIVOS: tática para a formação docente continuada}

Ser professor é compreender os sentidos da instituição escolar, integrar-se numa profissão, aprender com os colegas mais experientes. É na escola e no diálogo com os outros professores que se aprende a profissão. O registro das práticas, a reflexão sobre o trabalho e o exercício da avaliação são elementos centrais para o aperfeiçoamento e a inovação. São estas rotinas que fazem avançar a profissão (NÓVOA, 2009, p. 03).

Por conta do contexto de isolamento social causado pela pandemia da COVID-19, o atendimento presencial nas Unidades de Ensino da Rede Municipal de Biguaçu ficou suspenso desde o dia 17 de março de 2020. A partir desse momento a Secretaria Municipal de Educação de Biguaçu - SEMED, apresenta uma proposta de formação continuada para educação infantil, no intuito de objetivar

No mês de maio, iniciamos o trabalho remoto, que começou com a construção de um Plano de Ação Emergencial (CEIM PÁSCOA, 2020) com vistas a garantir a manutenção da comunicação e do vínculo entre os profissionais, as crianças e suas famílias. Este documento escolar, elaborado de forma coletiva, com a participação ativa da equipe administrativo-pedagógica desta Unidade, além de pensar sobre a forma de organizar os planejamentos e executar as propostas pedagógicas centradas nas brincadeiras e nas interações no modo "não presencial", funcionou como uma espécie de ferramenta reivindicatória, já que solicitou à SEMED a realização de formação docente continuada durante os meses em que permaneceríamos trabalhando remotamente.

Podemos ver em Ceim Páscoa (2020), que de forma a complementar o trabalho remoto que vinha sendo realizado em contexto pandêmico, a SE- 
MED ofereceu aos profissionais da Educação Infantil a Formação Continuada Descentralizada a Distância (BIGUAÇU, 2020b, p. 01), cujos objetivos foram assim descritos:

Objetivo geral: Propor um estudo e planejamento coletivo a partir dos currículos construídos/indicados pela legislação Nacional da Educação Infantil, bem como temáticas ligadas à Proposta Curricular do município de Biguaçu. Objetivos específicos: Discutir a respeito do currículo trabalhado na Educação Infantil, com a perspectiva de construir sugestões de trabalho interdisciplinares; Discutir os conceitos de infância e criança e processos avaliativos na Educação Infantil; Refletir sobre o conteúdo a ser estudado, em que o processo final tenha culminância em uma escrita por parte dos participantes.

Compreendemos este documento norteador, confeccionado por membros da Secretaria Municipal de Educação, como um repertório, ou uma prescrição que foi apresentada para as Unidades, entendida, a partir de Certeau (1994, p. 93), como uma estratégia oferecida pelo então "sujeito de poder e de querer" - a SEMED - como base que deveria orientar, produzir, mapear e impor então o processo de formação no subcampo das instituições de Educação Infantil.

No CEIM Páscoa, a equipe administrativo-pedagógica apropriou-se taticamente desta estratégia, ressignificando os princípios que norteiam tal documento, legitimando e deslegitimando práticas e constituindo um espaço singular de jogo, de formação, marcado pela criação e manutenção de grupos de estudos coletivos, que a partir da leitura e interpretação de textos de referência, deveriam debater sobre os temas elencados e avaliar os seus "modos de fazer" - na concepção certeauniana -, num exercício compartilhado de articulação entre teoria e prática, o qual resultaria em um outro artefato, a síntese coletiva.

Além dos currículos nacionais prescritos para a Educação Infantil, foram elencados outros temas, como práticas interdisciplinares, docência compartiIhada e a perspectiva da educação inclusiva para além da educação especial. A intenção é de que as tessituras resultantes venham compor o Projeto Político Pedagógico da Unidade bem como a própria Proposta Curricular da Rede em questão. A compreensão de que é também por meio das interações e trocas entre saberes, das reflexões acerca das práticas e das situações cotidianas que se dá a formação justifica a opção pelos grupos de estudos coletivos, já que, para Nóvoa (2009, p. 07), 
a formação deve contribuir para criar nos futuros professores hábitos de reflexão e de autorreflexão que são essenciais numa profissão que não se esgota em matrizes científicas ou mesmo pedagógicas, e que se define, inevitavelmente, a partir de referências pessoais.

Interessa relatar como o CEIM Páscoa vivenciou essa experiência, como se deu o processo de criação destes grupos, da sua organização e da sua produção textual. Disso se ocupam as subseções seguintes.

\section{Do planejamento}

Frente à estratégia posta, a primeira ação no sentido da tática foi pensar no planejamento. Para tanto, foi tecido o repertório específico da Unidade, o Documento Norteador para a Formação Continuada Descentralizada a Distância no CEIM Páscoa, (2020), que traz os objetivos da proposta:

Objetivo geral: proporcionar momentos de estudos coletivos sobre os currículos nacionais prescritos para a Educação Infantil e temáticas relacionadas à ampliação da Proposta Curricular do Município de Biguaçu, em perspectiva interdisciplinar e inclusiva, em tempos de pandemia, na modalidade "não presencial". Objetivos específicos: revisitar os currículos nacionais prescritos para a Educação Infantil: Lei de Diretrizes e Bases da Educação, Diretrizes Curriculares Nacionais para a Educação Infantil, Base Nacional Comum Curricular (Etapa Educação Infantil) e Parecer do Conselho Nacional de Educação (2020); estudar dois temas ligados à ampliação da Proposta Curricular do Município de Biguaçu: Práticas interdisciplinares na Educação Infantil e Educação Infantil em Perspectiva Inclusiva; elaborar sínteses escritas, articulando os estudos às práticas pedagógicas, como contribuição para a tessitura de um texto final sobre a formação realizada (CEIM PÁSCOA, 2020, p. 02).

Inicialmente, trabalhamos com o período entre os meses de junho a agosto, para os quais elegemos três grandes temas. Acordamos que estudaríamos um tema por mês, organizado em grupos de estudos coletivos semanais com a duração de 06 horas cada. Os encontros aconteceriam nas mesmas salas virtuais do Skype que utilizamos para as reuniões de planejamento compartilhado.

O horário ficou a ser definido por cada grupo. Decidimos, igualmente, que, na última semana de cada mês seria realizado o Grande Encontro Virtual Mensal, momento de socialização das sínteses produzidas pelos grupos, tam- 
bém de carga horária igual a 06 horas. Para este grande encontro, convidamos profissionais da área da Educação Infantil, como os professores Adilson de Ângelo e Aline Helena Mafra Rebelo, ambos da Universidade do Estado de Santa Catarina, e colegas da Rede Municipal de Ensino de Biguaçu, como Maria Koerich e Marília Pinto Garcia, que nos agraciaram com suas palestras e contribuições.

Dessa forma, para o mês de junho, ficou definido o tema Currículos Prescritos para a Educação Infantil; para julho, Práticas interdisciplinares na Educação Infantil e, para agosto, Educação Infantil em perspectiva inclusiva. Para cada tema, foram indicados textos de referência. A escolha destes textos foi feita pelas Articuladoras Gerais: Especialista em Assuntos Educacionais e Diretora da Unidade ${ }^{2}$. E, para cada um dos grupos, foi indicada uma Articuladora Interna, responsável pelo agendamento dos encontros, lista de presença e canal direto de diálogo com a Especialista:

Caberá aos grupos fazer o seu estudo, dialogar com seus pares e elaborar uma síntese que deve levar em conta a articulação dos textos estudados à prática pedagógica, numa perspectiva interdisciplinar. A cada sexta-feira a articuladora interna ${ }^{3}$ do seu grupo enviará à Especialista uma lista de presença e uma "notícia do andamento do estudo" (por exemplo: "na primeira semana, estudamos e discutimos os textos 01 e 02"). No Grande Encontro Virtual Mensal essas sínteses serão apresentadas e entregues oficialmente no dia seguinte (CEIM PÁSCOA, 2020, p. 06).

Os grupos ${ }^{4}$ foram organizados pela Especialista, que reuniu as professoras regentes, as auxiliares de sala e de ensino, as segundas professoras, de Educação Física, de Artes, a Técnica em Educação, a Diretora... enfim, grupos mistos, que deveriam se reunir semanalmente para compartilhar seus saberes, trocar impressões e interpretações sobre os textos, sempre no sentido de refletirem sobre a sua própria prática, ampliarem suas concepções e qualificarem o seu trabalho, além de elaborarem textos de síntese os quais devem compor os currículos prescritos como o Projeto Político Pedagógico da Unidade e servir de fonte também para a atualização da Proposta Curricular do Município.

\footnotetext{
${ }^{2}$ A partir do mês de agosto recebemos o reforço da participação de mais uma articuladora geral de formação, a professora Andréia Cristina dos Santos.

${ }^{3}$ Articuladoras Internas nomeadas pela Especialista.

${ }^{4}$ Como a professora de Língua Inglesa atende a outras três Unidades, ficou livre para escolher em qual delas participaria da formação continuada, por isso não participou no CEIM Páscoa.
} 


\section{Da seleção de textos e elaboração dos estudos dirigidos}

Para cada tema de estudo foram selecionados alguns textos e compartilhados com os grupos, com antecedência. São utilizados alguns canais de comunicação com a equipe do CEIM Páscoa, como o grupo de WhatsApp e o grupo no Gmail. Então, continuamos fazendo uso destas ferramentas para o compartilhamento de materiais referentes aos estudos.

No primeiro tema, tivemos como leitura obrigatória: a Lei de diretrizes e bases da educação nacional; as Diretrizes Curriculares Nacionais para a Educação Infantil; a Base Nacional Comum Curricular - Etapa Educação Infantil; e o Parecer do Conselho Nacional de Educação sobre a Reorganização do Calendário Escolar e da possibilidade de cômputo de atividades não presenciais para fins de cumprimento da carga horária mínima anual, em razão da Pandemia da COVID-19. E de leitura complementar: os Indicadores de Qualidade na Educação Infantil e os Campos de experiências na escola da infância: contribuições italianas para inventar um currículo de Educação Infantil brasileiro.

Para o segundo tema, a leitura obrigatória permeou os seguintes textos: a nota introdutória do livro Integração e Interdisciplinaridade no Ensino Brasileiro: Efetividade ou ideologia; A interdisciplinaridade como um movimento articulador no processo ensino-aprendizagem e A interdisciplinaridade na Educação Infantil. E, como leitura complementar: O que é interdisciplinaridade? e Interdisciplinaridade na educação de infância: a roda olímpica do movimento, expressão, corpo e ludicidade.

Este segundo tema se desdobrou em mais um, Docência Compartilhada, a partir da contribuição de uma das nossas palestrantes convidadas, a Especialista em Assunto Educacionais do Setor Pedagógico da SEMED, Marina K., que nos contemplou com indicações de referências acerca da temática. O tema foi estudado em setembro. Portanto, ainda não foi possível dar conta do estudo previsto sobre Educação Infantil em Perspectiva Inclusiva, o qual foi adiado para o mês de outubro, com expectativa de continuidade no próximo ano letivo, dada a sua abrangência e relevância, bem como a falta de previsão para retorno ao atendimento presencial nas nossas Unidades.

Com a inclusão da nova temática, nos debruçamos sobre os seguintes textos de leitura obrigatória: Docência compartilhada: do solitário ao solidário 
e Docência na Educação Infantil: uma análise das redes municipais no contexto catarinense. E como texto extra, Docência compartilhada: desafios e potencialidades do trabalho pedagógico na Educação Infantil. Das decorrências deste estudo podemos citar a tessitura de um dos outros capítulos deste livro, onde as autoras refletem sobre ensaios da prática da docência compartilhada no CEIM Páscoa, em contexto de pandemia.

Um dos artifícios utilizados pelas Articuladoras Gerais foi a elaboração de estudos dirigidos, baseados em questões norteadoras, para, de alguma forma, orientar os momentos coletivos, fomentar os debates e a reflexão sobre as práticas pedagógicas e, também, o exercício de síntese.

\section{Das sínteses coletivas}

Toda a formação encerra um projecto de acção. E de trans-formação. E não há projecto sem opções (NÓVOA, 1995, p. 33).

De acordo com os ensinamentos de Nóvoa (1995, p. 13), a formação docente continuada deve incentivar uma perspectiva crítico-reflexiva que proporcione aos professores as condições para a consolidação de um pensamento autônomo e que propicie dinâmicas de autoformação participada, sendo que "estar em formação implica um investimento pessoal, um trabalho livre e criativo sobre os percursos e os projectos próprios, com vista à construção de uma identidade, que é também uma identidade profissional".

Essa formação não se deve construir apenas pela acumulação de cursos, certificados ou técnicas, mas, se não principalmente, por meio da reflexividade crítica sobre as suas próprias práticas e também de (re)construção de uma identidade pessoal, num processo contínuo, interativo e dinâmico. Aqui os grupos de estudos coletivos são compreendidos e defendidos como espaços de formação mútua, nos quais cada professor é chamado a desempenhar, simultaneamente, o papel de formador e de formando, quando conta a sua experiência e ouve a do outro, numa troca na qual compartilham saberes.

As sínteses coletivas, produto final dos estudos individuais, dos encontros coletivos, dos debates e revisões de posturas, de ideologias e de concepções pedagógicas, são os registros do processo, trazem, em suas linhas, tessituras de práticas reavaliadas, refletidas, são os artifícios que provam a riqueza da tática 
utilizada para a formação continuada no CEIM Páscoa porque são indícios do esforço coletivo empreendido num contexto totalmente atípico e conturbado da pandemia COVID-19. Nesse contexto, os profissionais da educação tiveram que se reinventar, reconstruindo sua identidade pessoal e profissional, ávidos por manter o vínculo com as crianças e por buscar refletir sobre suas próprias práticas, qualificar seus saberes, a partir da troca com os seus pares, que, embora diferentes entre si, formaram aos outros ao mesmo tempo em que se formaram, numa parceria que tende a continuar, pós-contexto pandêmico.

\section{CONSIDERAÇÕES FINAIS}

A tessitura, confeccionada a quatro mãos, tentou divulgar uma das práticas pedagógicas que vem sendo desenvolvida na Rede Municipal de Educação de Biguaçu, em contexto pandêmico, de forma muito especial, a apropriação tática do CEIM Páscoa diante da estratégia de formação docente continuada oferecida pela rede em questão.

Pretendeu também fomentar o debate sobre a importância da formação docente continuada para a reflexão da prática pedagógica, sobretudo por meio de grupos de estudos coletivos, onde os professores compartilharam experiências, saberes e anseios e, para além da interpretação dos textos de referência, leram e refletiram sobre o seu próprio texto, o seu fazer pedagógico.

Esses momentos coletivos possibilitaram aos professores participantes construir coletivamente o conhecimento, bem como a opção de escolher aquilo que seria relevante como estudo do grupo, permitindo a construção de novos olhares para o ser professor profissional e o ser professor pesquisador.

\footnotetext{
Resumo: Este texto originou-se a partir da proposta de formação docente continuada desenvolvida na rede de ensino municipal de Biguaçu, em uma perspectiva de estudo nos treze centros de Educação Infantil, que delinearam uma rotina de encontros durante o período de isolamento social. Esta tessitura, de abordagem qualitativa e de cunho bibliográfico e documental analisa a estratégia da Secretaria Municipal de Educação de Biguaçu no sentido da formação docente continuada, e ressaltar os grupos de estudos coletivos como tática do CEIM Páscoa para este fim. Além do referencial teórico do campo da formação docente como Contreras (2012), bem como no âmbito do coronavírus no contexto da educação - Soares (2020) e Martins (2020), fundamenta-se também em Certeau (1994), Paulo Freire (1996), Nóvoa (1995; 2009) e Passeggi (2016). Com base também nos documentos escolares: planejamentos, estudos dirigidos e sínteses coletivas, pretendemos socializar a experiência vivida no Centro de Educação Infantil Municipal Professora Páscoa Régis Mendes em tempos de pandemia. As discussões e sínteses coletivas que derivaram deste processo de formação demonstram que a apropriação tática desta instituição de Educação Infantil foi produtiva e pode servir de inspiração para as demais Unidades, para além do contexto pandêmico.
} 
Palavras-chave: Grupos de Estudos Coletivos. Formação Docente Continuada. Estratégias e Táticas. Centro de Educação Infantil Municipal Professora Páscoa Régis-Mendes. Contexto de pandemia da COVID-19.

\begin{abstract}
This text originated from the proposal of continuing teacher education developed in the municipal education network of Biguaçu, in a perspective of study in thirteen Child Education centers, which outlined a routine of meetings during the period of social isolation. This structure, with a qualitative approach and bibliographic and documental nature, analyzes the strategy of the Municipal Department of Education of Biguaçu towards continuing teacher education, and emphasizes collective study groups as a tactic of CEIM Easter for this purpose. In addition to the theoretical framework in the field of teacher education such as Contreras (2012), as well as in the scope of the coronavirus in the context of education - Soares (2020) and Martins (2020), it is also based on Certeau (1994), Paulo Freire (1996) ), Nóvoa (1995; 2009) and Passeggi (2016). Also based on school documents: planning, directed studies and collective syntheses, we intend to share the experience lived at the Teacher Easter Régis Mendes Municipal Child Education Center in times of pandemic. The collective discussions and syntheses that resulted from this training process demonstrate that the tactical appropriation of this Early Childhood Education institution was productive and can serve as an inspiration for the other Units, beyond the pandemic context.
\end{abstract}

Keywords: Collective Study Groups. Continuing Teacher Training. Strategies and Tactics. Municipal Child Education Center Teacher Easter Régis Mendes. COVID-19 pandemic context.

\title{
REFERÊNCIAS
}

ANPED et al. Contra a descaracterização da Formação de Professores - Nota das entidades nacionais em defesa da Res. 02 /2015. Disponível em: anped.org.br/news/contra-descaracterizacao-da-formacao-de-professores-nota-das-entidades-nacionais-em-defesa-da. Acesso 16 de jun. 2021.

BIGUAÇU. Secretaria Municipal de Educação de Biguaçu. Plano de Atendimento Emergencial para Rede Municipal de Educação. Biguaçu, 2020a.

BIGUAÇU. Secretaria Municipal de Educação de Biguaçu. Formação Continuada para a Educação Infantil. Biguaçu, 2020b.

BIGUAÇU. Prefeitura Municipal. Decreto no. 69/2020, de 18 de março de 2020. Declara situação de Emergência e estabelece medidas de prevenção e combate ao COVID-19 e Regulamenta os horários e as escalas de trabalho na Administração do Município de Biguaçu e estabelece outras providências. Disponível em: https://leismunicipais.com.br/a/sc/b/biguacu/decreto/2020/6/69/ decreto-n-69-2020-declara-situacao-de-emergencia-e-estabelece-medidas-de-prevencao-e-combate-ao-covid-19-e-regulamenta-os-horarios-e-as-escalas-de-trabalho-na-administracao-do-municipio-de-biguacu-e-estabelece-outras-providencias. Acesso em: 13 out. 2020.

BRASIL. Ministério da Educação. Secretaria de Educação Básica. LDB: Lei de diretrizes e bases da educação nacional. Brasília: Senado Federal, Coordenação de Edições Técnicas, 2017.

BRASIL. Ministério da Educação - Conselho Nacional de Educação. Reorganização do Calendário Escolar e da possibilidade de cômputo de atividades não presenciais para fins de cumprimento da carga horária mínima anual, em razão da Pandemia da COVID-19, 2020c. Disponível em: https://www.semesp.org.br/wp-content/uploads/2020/05/Parecer-CNE-CP_5_2020. pdf. Acesso em: 28 maio 2020.

BRASIL. Medida Provisória no 934, de 10 de abril de 2020. Estabelece normas excepcionais sobre o ano letivo da educação básica e do ensino superior decorrentes das medidas para enfrentamento da situação de emergência de saúde pública de que trata a Lei no 13.979 , de 6 
de fevereiro de 2020d. Disponível em: https://www.in.gov.br/en/web/dou/-/medida-provisoria-n-934-de-1-de-abril-de-2020-250710591. Acesso em: 01 out. 2020.

BRASIL. Lei no 13.979, de 06 de fevereiro de 2020. Dispõe sobre as medidas para enfrentamento da emergência de saúde pública de importância internacional decorrente do coronavírus responsável pelo surto de 2019. Disponível em: http://www.planalto.gov.br/ccivil_03/_ato20192022/2020/lei/l13979.htm. Acesso em: 01 out. 2020.

CENTRO de Educação Infantil Municipal Professora Páscoa Régis Mendes. Documento Norteador Formação Docente Continuada Descentralizada a Distância - CEIM Páscoa. Biguaçu, 2020.

CENTRO de Educação Infantil Municipal Professora Páscoa Régis Mendes. Plano de Ação Emergencial. Biguaçu, 2020.

CERTEAU, Michel de. A invenção do cotidiano: artes de fazer. Tradução de Ephraim Ferreira Alves. Petrópolis: Vozes, 1994.

CONTRERAS, José. A autonomia de professores. São Paulo: Cortez, 2002.

FREIRE, Paulo. Pedagogia da Autonomia: saberes necessários à prática educativa. São Paulo: Paz e Terra, 1996.

MARTINS, João Rodrigo V. Educação como lócus da luta de classes na pandemia. In: SOARES. Sávia Bona V. Coronavírus, educação e luta de classes no Brasil. Editora Terra Sem Amos: Brasil, 2020. p. 15-19.

NÓVOA, António. Para uma formação de professores construída dentro da profissão. Revista de Educación, 2009. Disponível em: http://www.educacionyfp.gob.es/revista-de-educacion/dam/ jcr:31ae829a-c8aa-48bd-9e13-32598dfe62d9/re35009por-pdf.pdf. Acesso em: 25 ago. 2020.

NÓVOA, António. Formação de professores e profissão docente. In: NÓVOA, António (Org.). Os professores e a sua formação. 2. ed. Lisboa: Dom Quixote, 1995. p. 13-33. Disponível em: https://repositorio.ul.pt/bitstream/10451/4758/1/FPPD_A_Novoa.pdf. Acesso em: 14 set. 2020.

PASSEGGI, Maria da Conceição. Narrativas da experiência na pesquisa-formação: do sujeito epistêmico ao sujeito biográfico. Roteiro, v. 41, n. 1, p. 67-86, 23 mar. 2016. Disponível em: https:// portalperiodicos.unoesc.edu.br/roteiro/article/view/9267/pdf. Acesso em: 01 set. 2020.

SANTA CATARINA. Decreto Estadual 515, de 17 de março de 2020. Declara situação de emergência em todo o território catarinense, nos termos do COBRADE $n^{\circ}$ 1.5.1.1.0 - doenças infecciosas virais, para fins de prevenção e enfrentamento à COVID-19, e estabelece outras providências. Disponível em: https://www.legisweb.com.br/legislacao/?id=390995. Acesso em: 01 out. 2020.

SOARES, Sávia Bona V. Coronavírus e a modernização conservadora da educação. In: SOARES, Sávia Bona V. Coronavírus, educação e luta de classes no Brasil. Ceará; Piauí: Terra Sem Amos, 2020. p. 5-14.

Recebido em Setembro de 2021

Aprovado em Outubro de 2021 